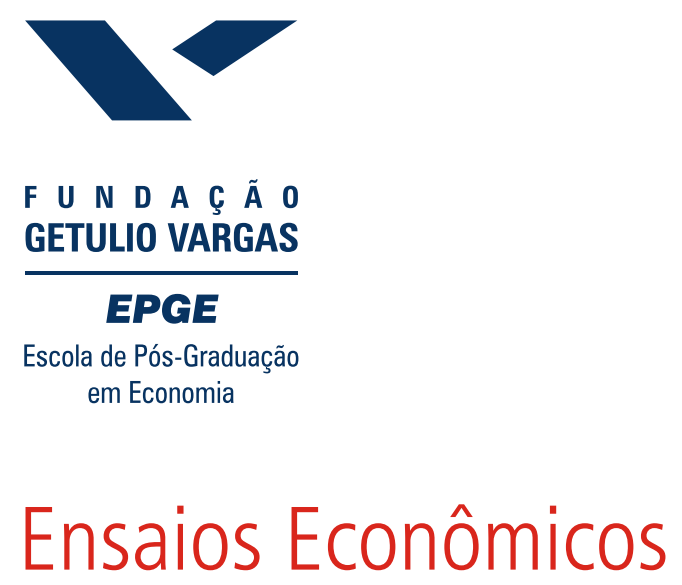

$$
\begin{aligned}
& \text { Escola de } \\
& \text { Pós Graduação } \\
& \text { em Economia } \\
& \text { da Fundação } \\
& \text { Getulio Vargas }
\end{aligned}
$$

Competitive Equilibrium Hyperinflation under Rational Expectations

Fernando de Holanda Barbosa, Alexandre Barros da Cunha, Elvia Mureb Sallum 
Os artigos publicados são de inteira responsabilidade de seus autores. As opiniões neles emitidas não exprimem, necessariamente, o ponto de vista da Fundação Getulio Vargas. 


\title{
Competitive Equilibrium Hyperinflation under Rational Expectations
}

\author{
Fernando de Holanda Barbosa \\ Professor of Economics \\ Getulio Vargas Foundation Graduate School of Economics \\ Alexandre Barros da Cunha \\ Assistant Professor \\ Ibmec School of Business \\ Elvia Mureb Sallum \\ Associate Professor \\ Institute of Mathematics and Statistics \\ University of SãoPaulo
}

\begin{abstract}
This paper shows that a competitive equilibrium model, where a representative agent maximizes welfare, expectations are rational and markets are in equilibrium can account for several hyperinflation stylized facts. The theory is built by combining two hypotheses, namely, a fiscal crisis that requires printing money to finance an increasing public deficit and a predicted change in an unsustainable fiscal regime.
\end{abstract}

Keywords and Phrases: Hyperinflation, Rational Expectations, Competitive Equilibrium, Fiscal Crisis.

JEL classification: E31, E42, E63. 


\section{Competitive Equilibrium Hyperinflation under Rational Expectations}

Fernando de Holanda Barbosa*

Alexandre Barros da Cunha**

Élvia Mureb Sallum ${ }^{* * *}$

\section{INTRODUCTION}

Cagan's (1956) seminal work provided the first attempt to explain the hyperinflation phenomenom. That essay was so influential that small variations of Cagan's model can be found in several textbooks such as Blanchard and Fischer (1989), Obstfeld and Rogoff (1996), Romer (2001) and Sargent (1987).

Cagan's model is capable of generating hyperinflation under two types of expectation mechanisms: adaptive and rational. Both mechanisms have the same reduced form. Both are unsatisfactory because adaptive expectations yield systematic forecasting errors, while rational expectations need to be combined with a partial adjustment mechanism in the monetary market. Moreover, either mechanism requires violation of the government budget constraint to generate a hyperinflation. That is, in Cagan's model, a hyperinflation is not a competitive equilbrium outcome.

Marcet and Nicolini (2003) adopted a simple monetary model composed by a money demand equation, a government budget constraint and an exchange rate rule. They assumed that agents in the model were boundedly rational. They showed that such a model could generate recurrent episodes of high inflation, as observed in several Latin American countries in the eighties and nineties. Zarazaga (1993) obtained similar results in a game

\footnotetext{
Professor of Economics, Getulio Vargas Foundation Graduate School of Economics. Email: fholanda@fgv.br.

*** Assistant Professor, Ibmec Business School.

*** Associate Professor, Institute of Mathematics and Statistics, University of São Paulo.
} 
theoretical setup. He assumed that players did not have full information on the distribution of the seignorage proceeds.

We summarize the current knowledge on hyperinflaton in the following way. In standard macro models, it is necessary to impose a deviation from rational expectations and/or to violate the government budget constraint for the model to generate hyperinflation. In other types of models, the hyperinflation may arise as a consequence of agents not being fully informed.

The main contribution of this paper is to show that a standard macroeconomic model with rational expectations is capable of displaying a hyperinflation as a competitive equilibrium outcome. To achieve that result, we introduced two major features in our model: a fiscal crisis that requires printing money to finance an increasing public deficit and a predicted change in an unsustainable fiscal regime.

One of the features of Cagan's model that, under our point of view, contributed to its long lasting influence is the fact that its solution provides an unbounded path for the inflation rate. Clearly, an inflation path that diverges to infinite will qualify as a hyperinflation process under any sounding definition of hyperinflation.

Neither Marcet and Nicolini (2003) nor Zarazaga (1993) models display an explosive inflation trajectory as an equilibrium outcome. This is not necessarily the case in our model. If the demand for money is inelastic with respect to the nominal interest rate, then the competitive equilibrium of our model may display an explosive inflation path.

We want to emphasize that our model is consistent with several hyperinflation stylized facts. Namely, the model is able to match the following features:

1. the real stock of money approaches zero;

2. the rate of inflation grows unboundedly;

3. the public deficit is financed by issuing money; 
4. hyperinflation duration is variable and depends on the fiscal conditions of each experience;

5. hyperinflation stops overnight through a change in the monetary policy regime. ${ }^{1}$

The fiscal crisis is the source of hyperinflation and we may paraphrase Friedman [(1970), p.25] and state that hyperinflation is always and everywhere a fiscal phenomenon, in the sense that a hyperinflation caused by a bubble has not been observed. The fiscal crisis is taken as given and there will be no attempt in this paper to explain the reasons that led a society to choose such a course of action. There is no doubt that institutions as well as economic policies should be explained by economic theory, since they are the outcome of choices and interaction among different groups of the society. This topic, however, is in the realm of political economy and will not be addressed here. The public knows that the intertemporal government budget constraint, under this fiscal crisis, is not sustainable in the long run and therefore expects a policy regime switch to occur in the near future.

Before turning to the theory, let us comment on three important points made by Cagan that has shaped both the empirical and theoretical studies on hyperinflation. First, Cagan's demand function for real cash balances yields a rate of inflation that maximizes inflation tax revenue. He observed that the average rate of rise in prices in the experiences he examined were well above the constant rates that would have maximized inflation tax revenue. This puzzle led several researchers (e.g. Bruno and Fischer (1990); Sargent and Wallace (1987)) to suggest solutions that could help understand the reasons why the government was operating on the wrong side of the Laffer curve. This puzzle may indeed be a pure statistical artifact implied by his maintained hypothesis. In the model we work

\footnotetext{
${ }^{1}$ See Bresciani-Turroni (1937), Cagan (1956), and Sargent (1982), for an account of stylized facts observed in several European hyperinflation experiences.
} 
out in this paper there is no such a puzzle because we are not convinced that Cagan's functional form is a stylized fact of hyperinflation experiences.

Secondly, Cagan (1956, pp. 77/78) remarked that "In the unsettled conditions following the two world wars, governments were too weak to enact adequate tax programs and to administer them effectively. Issuing money was a method of raising revenue...[that] does not require detailed legislation and can be administerd very simply". This statement is a good description of the fiscal crisis that underlies every hyperinflation, but previous works were not able to deal with it in a proper framework because they took this statement at face value. This paper interprets the fiscal crisis as the infeasibility of the intertemporal government budget constraint in the long run, under the economic policy regime in place and it shows that the inflation rates observed in hyperinflation experiences do not attain the maximum of inflation tax revenue that could be collected from society.

Thirdly, Cagan excluded some of the observations near the end of the hyperinflations because they could not be fitted by his model. He offered two hypotheses to explain these observations. The first assumes that individuals expect a currency reform, so prices would not go on rising for long, and they would hold more cash balances than the amount predicted by his demand for money equation. Flood and Garber (1980) pursued this hypothesis and they developed a theory of monetary reform. However, their model lacks microfoundations, e.g., the expected rate of inflation (the opportunity cost of holding money) is affected by the incoming monetary reform but this premium on the currency reform is not derived from first principles. The second hypothesis suggested by Cagan to explain the failure of his equation to account for the final months of some hyperinflations was that the data would not conform to his functional form. The model to be presented in this paper follows Cagan's second hypothesis, but also takes into consideration the fact that individuals in a hyperinflation environment knows that a currency reform will occur in 
the near future. The fact that the public expects a regime switch does not need to imply that the opportunity cost of holding money decreases as the time of the currency reform gets closer, since the interest rate does not necessarily have to include a premium on the currency reform.

This paper is organized as follows. Section 2 gives an overview of Cagan's model and some of its underlying hypotheses that have been overlooked in the literature. Section 3 presents a theoretical model that yields a competitive equilibrium hyperinflation path. Section 4 presents the solution of that model. Section 5 concludes. Technical issues are discussed in Appendixes A, B and C.

\section{CAGAN'S MODEL OF HYPERINFLATION}

Four equations constitute Cagan's famous model:

$$
\begin{aligned}
& \dot{m}=f-m \pi \\
& \log m=k-\alpha \pi^{e} \\
& \dot{\pi}^{e}=\beta\left(\pi-\pi^{e}\right) \\
& f=f(t)
\end{aligned}
$$

The first equation states that the public deficit $f$ is financed by issuing money; the second is the demand for money where the real quantity of money $m(=M / P)$ depends on the expected rate of inflation $\pi^{e}$ according to a semi-logarithmic functional form; the third is the adaptive expectation mechanism, and the fourth equation stands for the fiscal crisis. By taking derivatives of the second equation with respect to time, and taking into account the adaptive expectation mechanism we get: 


$$
\frac{\dot{m}}{m}=-\alpha \dot{\pi}^{e}=-\alpha \beta\left(\pi-\pi^{e}\right)=-\alpha \beta \pi+\alpha \beta \pi^{e}
$$

which can be written as,

$$
\frac{\dot{m}}{m}=-\alpha \beta \pi+\beta k-\beta \log m
$$

when we use the value of $\pi^{e}$ from the demand for money function. The rate of inflation is obtained by combining this expression with the first equation of the model. That is:

$$
\pi=\frac{1}{1-\alpha \beta}\left(\frac{f}{m}-\beta k+\beta \log m\right)
$$

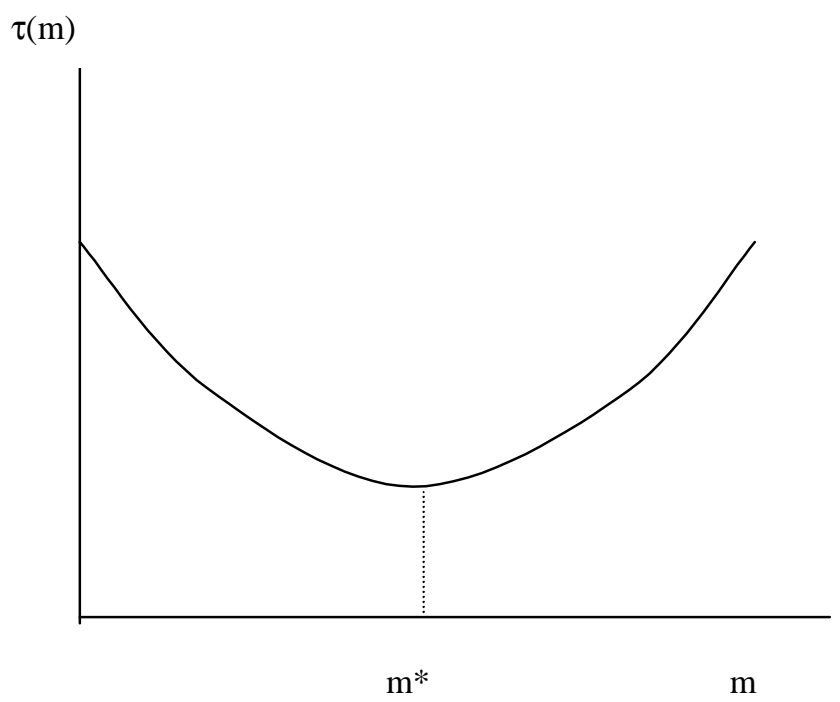

Figure 1

The inflation tax revenue $\pi(m)$ results from multiplying the inflation rate $(\pi)$ by the real quantity of money $(m)$ :

$$
\tau(m)=\frac{1}{1-\alpha \beta}(f-\beta k m+\beta m \log m)
$$


The derivatives of $\tau(m)$ with respect to $m$ are

$$
\frac{d \tau(m)}{d m}=\frac{1}{1-\alpha \beta}(-\beta k+\beta(\log m+1)), \quad \frac{d^{2} \tau(m)}{d m^{2}}=\frac{\beta}{(1-\alpha \beta) m}>0
$$

This inequality assumes that $1-\alpha \beta>0$, otherwise hyperinflation would not be feasible. Thus, the inflation tax function is convex, with a minimum at $m^{*}=\exp (k-1)$, and it increases when $\mathrm{m}$ approaches to zero. ${ }^{2}$ Figure 1 shows that the inflation tax function has a $\mathrm{U}$ shape. This function is completely different from the bell shaped Laffer curve of Cagan's demand for money functional form, when the expected rate of inflation is equal to the actual rate of inflation.

By combining the inflation tax revenue function with the first equation of Cagan's model we get the nonlinear differential equation:

$$
\dot{m}=-\frac{\alpha \beta}{1-\alpha \beta} f(t)+\frac{\beta k m}{1-\alpha \beta}-\frac{\beta}{1-\alpha \beta} m \log m
$$

This model yields a hyperinflation path when the fiscal crisis function $f(t)$ has the following specification,

$$
f(t)=\left\{\begin{array}{l}
f_{o}<f^{*}, \quad \text { if } t<t_{0} \\
\bar{f}>f^{*}=\frac{e^{k-1}}{\alpha}, \text { if } \quad t \geq t_{0}
\end{array}\right.
$$

where $t_{0}$ is the time that hyperinflation begins. The phase diagram of Figure 2 gives the graphic solution of the differential equation, and shows the dynamics of hyperinflation.

\footnotetext{
2 This shape is consistent with Cagan's (1956, p.79) statement: "The [tax] revenue was high at the start, when the expected rate of price increases was still low; tended to decline in the middle, as the expected rate started to rise considerably; and rose near the end, when the rate of new issues skyrocketed."
} 
Before the fiscal crisis, the economy is in equilibrium at point A. When the public deficit to be financed by money increases from $f_{o}$ to $\bar{f}$, the economy jumps to point $\mathrm{B}$, and enters a hyperinflation path.

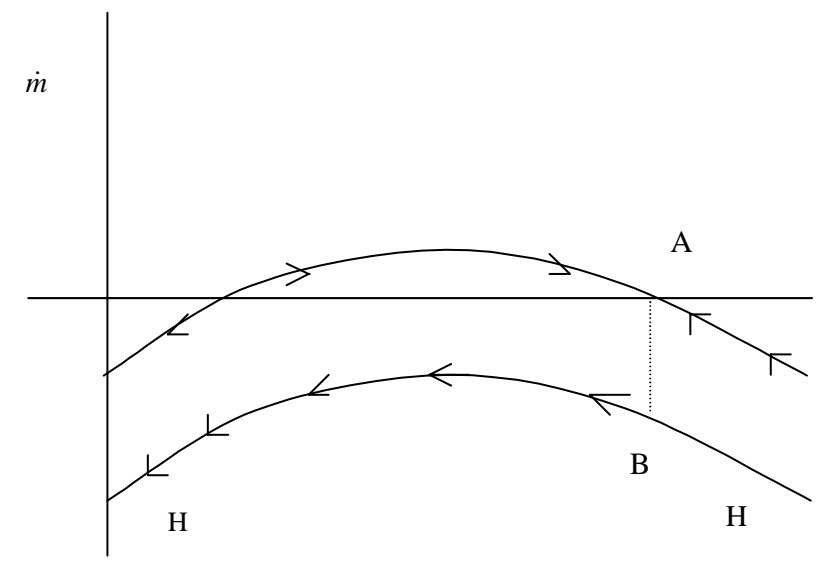

Figure 2

As shown in Figure 1, inflation tax revenue increases and goes to a finite number when the real quantity of money approaches zero. Therefore, Cagan had implicitly assumed that real quantity of money was an inelastic function of the observed inflation rate. We show in Appendix $\mathrm{C}$ that the ability of the model to generate an unbounded path for the inflation depends on the hypothesis that the demand for real balances is inelastic with respect to the interest rate.

\section{HYPERINFLATION: A THEORETICAL FRAMEWORK}

Hyperinflation is seen by the public to be unsustainable in the long run at least for two reasons. First, if the fiscal regime goes on forever it violates the intertemporal budget constraint of the government. Second, because money is essential to the functioning of the 
economy. Therefore, the public predicts that at some point in the near future a stabilization program will stop the hyperinflation process. However, the timing of the stabilization is unknown and to deal with this fact the model has to be stochastic. Thus, the probability mechanism of a regime change belongs to the information set of the representative agent. This uncertainty will be described by the distribution function $F(t)$, which gives to each instant $t$ the probability that a policy regime switch will occur before or at that moment $t$.

The public knows that the switch will occur at most at the instant $t_{h}$. Thus, the distribution function $F(t)$ is defined on the interval $\left[0, t_{h}\right]$. To make the exposition easier, we assume that $t_{h}$ is exogenous. In Appendix $C$ we extend the analysis to the case in which $t_{h}$ is endogenous.

The economic policy regime switch anticipated by the public will have the following characteristics: i) the central bank will stop issuing money to finance the public deficit; ii) the level of government expenditures will remain the same and will be financed by lump sum taxes; iii) the price level will be stabilized and the central bank will increase the stock of money once and for all at the moment of stabilization, and then iv) the central bank will hold the stock of money constant afterwards.

Thus, the nominal stock of money at the moment of stabilization $T$ is given by,

$$
M(T)=M\left(T_{-}\right)+\Delta M(T)=M(0)+\int_{0}^{T} z(x) d x+\Delta M(T)
$$

where $M(x)$ is the stock of money at the instant $x, z(x)$ is the additional flow of money at period $x$, and $\Delta M(T)$ is the once and for all increase in the stock of money at the moment of stabilization. The representative agent maximizes the expected value of the discounted 
flow of utilities, ${ }^{3}$

$$
\int_{0}^{t_{h}}\left\{\int_{0}^{T} e^{-\rho t}\left[u(c)+v\left(\frac{M}{P}\right)\right] d t+\frac{1}{\rho} e^{-\rho T}\left[u_{s}(y-g)+v_{s}\left(\frac{M_{T}}{P_{T}}\right)\right]\right\} d F(T)
$$

where $\rho$ is the rate of time preference, the utility function depends on consumption $(c)$ and the services provided by money $(m=M / P, M$ is the nominal stock of money and $P$ is the price index), and a subscript $s$ on a function denotes its value after stabilization has taken place. We assume that the representative agent has constant levels of consumption and real stock of money from the point of stabilization onward. The functions $u(c)$ and $v(m)$ are concave and have the traditional properties. The agent maximizes (1) subject to the flow restriction,

$$
y=c+\tau-D(t) \Delta \tau(T)+\frac{z}{P}+D(t) \frac{\Delta M_{T}}{P_{T}}
$$

and the stock restriction,

$$
M(t)=M(0)+\int_{0}^{t} z(x) d x
$$

where $D(t)=0$, if $t \neq T$, or $D(t)=1$, if $t=T, \tau$ is a lump sum tax, $c$ is consumption, $y$ is real income and $\Delta \tau(T)$ is the transfer made by the government at stabilization time.

The solution to this problem (see Appendix A and Drazen and Helpman (1990), and the references cited there, for more details), show that at each moment before the policy regime switch takes place, the nominal rate of interest is equal to the marginal rate of substitution of consumption for money,

\footnotetext{
3 This model is an extension of the model presented by Drazen and Helpman (1990). They analysed situations where monetary and fiscal policies are known to be not sustainable in the long run. However, they did not use their framework to provide a model of hyperinflation as done in this paper.
} 


$$
\frac{v^{\prime}(m)}{u^{\prime}(c)}=r=\rho+\pi
$$

When there is uncertainty about the timing of a regime change the interest rate may include a risk premium. If at the time of stabilization the price level would be allowed to have a downward jump, for example, the agent would expect a capital gain and the risk premium would be negative. If at the time of stabilization government spending would be cut, consumption would increase, the marginal utility of consumption decreases, and the rate of interest would include a positive risk premium. ${ }^{4}$ There is no interest rate risk premium in equation (4) because the stabilization program will allow neither a price jump nor a change in the flow of consumption.

The market for goods and services is in equilibrium when output is equal to the sum of consumption and government $(g)$ expenditures:

$$
y=c+g
$$

The government finances its constant level of expenditures through a lump sum tax and issuing money:

$$
g=\tau+D(f)
$$

where $D(f)=f$, if $t<T$, or $D(f)=0$, if $t \geq T$, and

$$
f=\frac{z}{P}=\frac{\dot{M}}{P}=\dot{m}+m \pi
$$

\footnotetext{
${ }^{4}$ The analysis of this case will not be pursued here, since the qualitative results would not change.
} 
The public deficit, financed by isssuing money, increases through time according to: ${ }^{5}$

$$
f=f(t), \quad \dot{f}>0, \quad f \leq g, \lim _{t \rightarrow \infty} f(t)=\bar{f}>\bar{s}
$$

We assume that the deficit to be financed by money can be at most equal to the level of government expenditures. The last inequality in the expression above characterizes the fiscal crisis. It says that as time goes by, the fiscal deficit to be financed by money becomes larger than the maximum amount of inflation tax $(\bar{s})$ that can be collected from society.

\section{MODEL SOLUTION}

The economic model can be summed up by the following system of four equations:

$$
\begin{gathered}
\dot{m}=f-m \pi \\
r=\frac{v^{\prime}(m)}{u^{\prime}(c)} \\
r=\rho+\pi \\
f=f(t)
\end{gathered}
$$

\footnotetext{
${ }^{5}$ This hypothesis is consistent with the German hyperinflation experience, as reported by Bresciani-Turroni (1937,p.74): “...in October 1923 an extraordinary phenomenon in the history of the public finance appeared, the complete atrophy of the fiscal system (sic). In the last decade of that month the ordinary receipts covered about 0.8 per cent of the expenses; the State now obtained money exclusively through the discount of Treasury bills."
} 
In the first equation, the public deficit is financed by money; in the second equation, the demand for money is written in implicit form; in the third, the Fisher equation is stated; in the fourth, the public deficit financed by money changes through time according to the function $f(t)$, which tries to capture the fiscal crisis. By combining equations (5), (6), (7) and (8) we get:

$$
\dot{m}-\rho m=f-m r=f(t)-s(m), \text { if } t<T
$$

This differential equation can be written as,

$$
m(t)=m\left(T_{-}\right) e^{-\rho(T-t)}+\int_{t}^{T} e^{-\rho(\tau-t)}[s(m)-f(\tau)] d \tau,
$$

which is the intertemporal government budget constraint, and $m\left(T_{-}\right)$is the real quantity of money just before stabilization takes place. The function $s(m)$ measures the cost of money services:

$$
s(m)=m r=m \frac{v^{\prime}(m)}{u^{\prime}(c)}
$$

We assume that the money demand equation has interest rate elasticity, in absolute value, between zero and one. As discussed in Barbosa and Cunha (2003), this hypothesis implies that $\lim _{m \rightarrow 0^{+}} m v^{\prime}(m)>0$. Hence, $s(m)$ must satisfy the following properties on the function $\left.s(m): a) \lim _{m \rightarrow 0} s(m)=\bar{s}>0, b\right) s^{\prime}(m) \leq 0$. The first says that the inflation tax $(m \pi)$ goes to a positive value when the real quantity of money approaches zero. The second condition assumes that the cost of money services increases when the real quantity of 
money decreases. As a consequence, as the real balances goes to zero the inflation tax is bounded away from zero. In fact, equations (6) and (7) imply that $m v^{\prime}(m)=(\rho m+\pi m) u^{\prime}(c)$. In Appendix $\mathrm{C}$ we relax the hypothesis that the money demand is inelastic with respect to the nominal interest rate.

Before we provide a general solution to the model it will be interesting to analyse the particular case where the public deficit to be financed by money is constant, which has been the usual situation considered in the literature (see Bruno and Fischer (1990), Kiguel (1989), Romer (2001), Sargent and Wallace (1987)). Under this assumption the differential equation (9) has the phase diagram of Figure 3, since ${ }^{6}$

$$
\frac{d \dot{m}}{d m}=\rho-\frac{d s(m)}{d m} \geq 0
$$

In this diagram, we examine three hypotheses. The first $(A A)$ supposes that the public deficit to be financed by money is less than the maximum value of the services provided by money. The model has a steady-state equilibrium where the inflation rate is constant. The second hypothesis $(O B)$ assumes that the public deficit to be financed by money is equal to the limit of the function $s(m)$ when the real quantity of money approaches zero. The model now has a hyperinflation steady-state equilibrium. The third hypothesis $(C C)$ presupposes that the public deficit to be financed by money is greater than the maximum of the value of the services provided by money. The economic agents know this fact beforehand and they will try to get rid immediately of the stock of money they hold. Thus, the model yields hyperinflation, which is not a steady-state equilibrium.

We may conclude that a constant public deficit to be financed by money can yield hyperinflation. However, this condition cannot bring about a hyperinflation path, but only 
an instantaneous hyperinflation. This fact has not been observed in hyperinflation experiences that have occurred in the past century. Furthermore, there is no evidence that a constant public deficit to be financed by money should be a good working hypothesis (see Note 5).

The nonautonomous differential equation (9) is nonlinear. From a mathematical point of view it is convenient to define the function $s(m)$ for all real numbers, and not only for nonnegative numbers, such as $s(m) \geq \bar{s}-\delta m$ for $m \leq 0$, where $s^{\prime}(0)=-\delta \leq 0$. When $\dot{m}=0$, we define $m_{t}$ according to,

$$
\rho m_{t}+f(t)-s\left(m_{t}\right)=0
$$

and by the implicit function theorem it follows that

$$
\frac{d m_{t}}{d t}=\frac{-f^{\prime}(t)}{\rho-s^{\prime}\left(m_{t}\right)}<0
$$

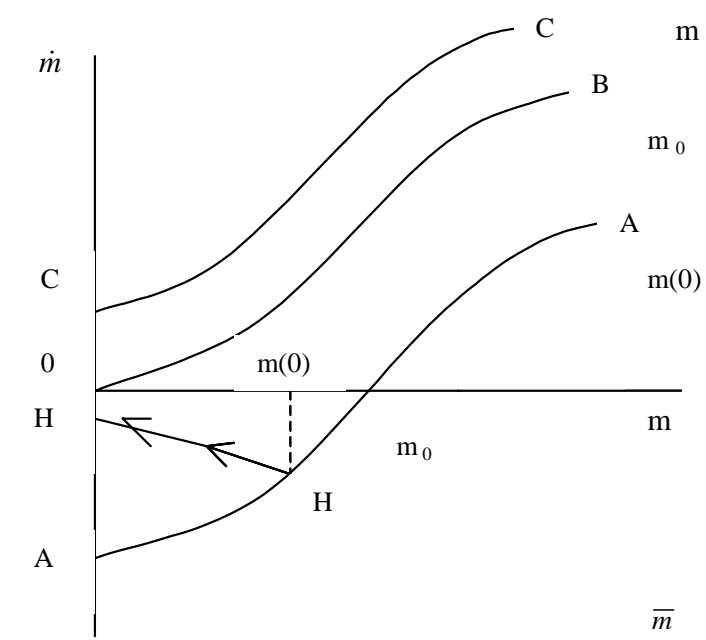

Figure 3

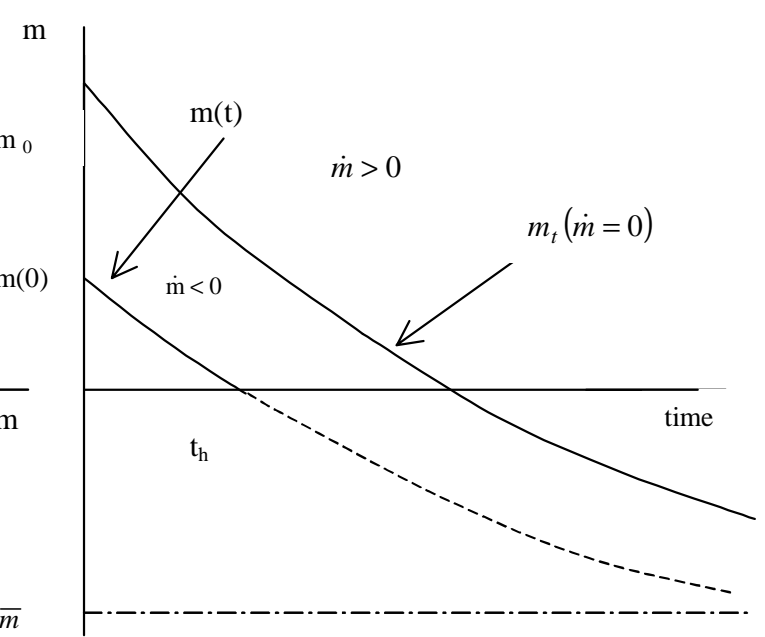

Figure 4

\footnotetext{
${ }^{6}$ The shape of this phase diagram depends upon the second derivative of $d m / d t$ with respect to $m$. This is an empirical question. Thus, other shapes could be used instead of the one we use in Figure 1.
} 
Thus, $m_{t}$ is a nonincreasing function and $\lim _{t \rightarrow \infty} m_{t}=\bar{m}$, where $\rho \bar{m}+\bar{f}-s(\bar{m})=0$. The value of $\bar{m}$ can be positive, zero or negative. Let us analyze the last case because it yields hyperinflation paths that correspond to real world experiences. Figure 4 is a phase diagram that represents the solution of the nonautonomous differential equation (9), and we will be able through the variable $m_{t}$ to partition the phase space into regions in which the real stock of money decreases or increases over time. Therefore, Figure 4 denotes paths of the real quantity of money against time and it shows the case when $\bar{m}<0$. The curve $m_{t}$ divides the plane into two regions, in the upper part the real stock of money increases $(\dot{m}>0)$ and in the lower part it decreases $(\dot{m}<0)$.

The hyperinflation path must be consistent with the monetary reform ocurring at the last moment. Thus, the initial value of the real quantity of money $(m(0))$ is the same regardless of the uncertain timing of the monetary reform (see Appendix B for details). The diagram of Figure 4 describes a situation where hyperinflation lasts the maximum amount of time that the fiscal situation allows. The hyperinflation path of Figure 4 that ends at $t_{h}$, corresponds to the path $H H$ of the phase diagram of Figure 3.The curve $A A$ now correponds to the initial fiscal deficit $f(0), O B$ to the maximum amount of inflation tax that can be collected and $C C$ corresponds to $f(\infty)=\bar{f}$. Given the initial real quantity of money $m(0)$, the curve $A A$ shows that the change of the real quantity of money is negative at the beginning of the fiscal crisis. Thus, the real quantity of money decreases. The deficit financed issuing money increases shifting the $A A$ curve towards the origin and the economy moves along the $H H$ path. The end of hyperinflation may occur before $H H$ cuts the vertical axis (earlier than $t_{h}$ ), since the timing of the regime switch is unpredictable. 
However, the dynamics of hyperinflation will follow the path described above until the time of the currency reform.

\section{CONCLUSION}

No currently available model in the literature can provide an equilibrium hyperinflation without departing from rational expectations and/or fully informed agents. We have shown in this paper that the hyperinflation phenomenon is consistent with a competitive equilibrium with rational expectations and complete information. The driving force behind that result is an increasing fiscal deficit to be financed by issuing money. The public knows beforehand that the economic policy regime will break down since the fiscal crisis is not tenable. Despite anticipating a possibly unbounded path for the inflaton rate, people optimally choose to carry a small, but positive, amount of money.

Some implications of our model are consistent with the facts observed in several hyperinflation experiences during the twentieth century. Among them are: a) hyperinflation duration depends upon the degree and velocity of the fiscal crisis, on the maximum amount the economy can collect from inflation tax and on the real rate of interest; b) inflation inertia is caused only by the inertia of the fiscal crisis; c) the end of the hyperinflation occurs before the deficit financed issuing money reaches the maximum value of the inflation tax; d) the hyperinflation path is such that at the moment that the real stock of money approaches zero $(m \rightarrow 0)$, its rate of change is negative $(\dot{m}<0)$.

The theory of hyperinflation presented in this paper can address the issue of

defining hyperinflation, where there is no need for an arbitrary threshold inflation rate as in Cagan's classical definition. Hyperinflation will be defined as beginning in the month where the intertemporal budget constraint is not sustainable, conditional on no change in 
the economic policy regime and as ending in the month where this constraint is satisfied. Recent research developed to test the sustainability of the public debt can be applied to examine the question that is at the core of hyperinflation: does the size of the government deficit to be financed by money imply that the intertemporal budget constraint is not sustainable if a policy regime switch does not occur? ${ }^{7}$

\section{Appendix A}

We consider an economy in which a representative agent maximizes the discounted flow of utility (1), with respect to the variables $\mathrm{c}, \mathrm{z}, \mathrm{M}$ and $\Delta \mathrm{M}(\mathrm{T})$, subject to the restrictions (2) and (3). The Lagragian form of this problem is:

$$
\begin{aligned}
& \int_{0}^{t_{h}}\left\{\int_{0}^{T} e^{-\rho t}\left[u(c(t))+v\left(\frac{M(t)}{P(t)}\right)\right] d t+\frac{1}{\rho} e^{-\rho T}\left[u_{s}(y-g)+v_{s}\left(\frac{M_{0}+\int_{0}^{T} z(x) d x+\Delta M(T)}{P(T)}\right)\right]\right. \\
& +\int_{0}^{T} \lambda(t)\left[y-c(t)-i(t)+D(T) \Delta \tau(T)-\frac{z(t)}{P(t)}-D(T) \frac{\Delta M(T)}{P(T)}\right] d t \\
& \left.+\int_{0}^{T} \gamma(t)\left[M(0)+\int_{0}^{t} z(x) d x-M(t)\right] d t\right\} d F(T)
\end{aligned}
$$

where $\lambda(t)$ and $\gamma(t)$ are Lagrange multipliers for each restriction. The first order conditions are given by:

$$
\int_{0}^{t_{h}}\left[e^{-\rho t} u^{\prime}(t)-\lambda(t)\right][1-F(t)] d t=0
$$

\footnotetext{
${ }^{7}$ See, for example, Trehan and Walsh (1991) for applications of these tests to U.S. federal budget and current account deficits.
} 


$$
\begin{gathered}
\int_{0}^{t_{h}}\left[e^{-\rho t} \frac{v^{\prime}(t)}{P(t)}-\gamma(t)\right][1-F(t)] d t=0 \\
\frac{\lambda(t)}{P(t)}=\int_{t}^{t_{h}}\left[\frac{1}{\rho} e^{-\rho T} \frac{v^{\prime}(T)}{P(T)}+\int_{t}^{T} \gamma(x) d x\right] \frac{d F(T)}{1-F(t)}
\end{gathered}
$$

It follows from equations (A1) and (A2) that:

$$
e^{-\rho t} u^{\prime}(t)=\lambda(t) \quad \text { and } \quad e^{-\rho t} \frac{v^{\prime}(t)}{P(t)}=\gamma(t)
$$

The derivative of (A3) with respect to time, taking into account these two last expressions and the fact that marginal utility of consumption is constant, can be written as:

$$
\frac{v^{\prime}(m(t))}{u^{\prime}(c(t))}=\rho+\pi+\frac{F^{\prime}(t)}{1-F(t)}\left[1-\frac{v_{s}^{\prime}(t)}{\rho u_{s}^{\prime}(t)}\right]
$$

Since $v_{s}^{\prime}(t) / u_{s}^{\prime}(t)=\rho$, we may conclude that the nominal rate of interest is equal to the marginal rate of substitution of consumption for money:

$$
\frac{v^{\prime}(m(t))}{u^{\prime}(c(t))}=\rho+\pi
$$

\section{Appendix B}

Consider the differential equation (10). Setting $t=0, T=t_{h}$ and using the fact that $m(t) \rightarrow$ 0 as $t \rightarrow t_{h}, t<t_{h}$, one obtains 


$$
m(0)=\int_{0}^{t_{h}} e^{-\rho t}[s(m(t))-f(t)] d t
$$

Define $\tilde{f}\left(t_{h}\right)$ according to $\tilde{f}\left(t_{h}\right)=\int_{0}^{t_{h}} e^{-\rho t} f(t) d t$. Using this equality and the definition of $s(m)$, it is possible to rewrite (B1) as

$$
m(0)=\frac{1}{u^{\prime}(c)} \int_{0}^{t_{h}} e^{-\rho t} m(t) v^{\prime}(m(t)) d t-\tilde{f}\left(t_{h}\right)
$$

This equation should pin down both $m(0)$ and the entire path $m(t)$ for $t \in[0, T]$. The properties of the function $v$ determine whether the solution is unique or not. We will provide an example with a single solution and another one with a continuum of solutions.

Assume that $v(m)=\log m$. For this particular $v$, the solution is unique. To verify this, observe that (B2) becomes

$$
m(0)=\frac{1}{\rho u^{\prime}(c)}\left(1-e^{-\rho t_{h}}\right)-\tilde{f}\left(t_{h}\right)
$$

This equation uniquely determines $m(0)$. To see that the path $m(t)$ is unique too, it suffices to observe that the same procedure used to determine $m(0)$ also yields a unique value for $m$ at any date $t>0$. In other words, equation (B2) must also hold if 0 is replaced by a generic date $t$. The solution is unique in the previous example because $m v^{\prime}(m)$ is constant (i.e., the cost of money services is constant).

Consider the case in which $v(m)=\log m+2 m^{0.5}$ and $t_{h}=1$. Equation (B2) becomes

$$
m(0)=\frac{1}{u^{\prime}(c)} \int_{0}^{1} e^{-\rho t}[1+\sqrt{m(t)}] d t-\tilde{f}(1)
$$


Assume that

$$
\tilde{f}(1) \leq\left[\frac{\int_{0}^{1} e^{-\rho t}(1-t) d t}{2 u^{\prime}(c)}\right]^{2}+\frac{1-e^{-\rho}}{\rho u^{\prime}(c)} .
$$

Let $a$ be a number belonging to $(0,1)$ and $m_{0}$ any positive number. Consider the path

$$
m(t)=m_{0}(1-t)^{2 a} .
$$

Observe that $m(0)=m_{0}$ and $m\left(1_{-}\right)=0$. It will be shown that (B6) provides uncountable many solutions for (B4). Fix $a$. From (B4), construct the equation

$$
m_{0}-\frac{\int_{0}^{1} e^{-\rho t}(1-t)^{a} d t}{u^{\prime}(c)} \sqrt{m_{0}}+\tilde{f}(1)-\frac{1-e^{-\rho}}{\rho u^{\prime}(c)}=0
$$

Consider the second-degree equation

$$
x^{2}-\frac{\int_{0}^{1} e^{-\rho t}(1-t)^{a} d t}{u^{\prime}(c)} x+\tilde{f}(1)-\frac{1-e^{-\rho}}{\rho u^{\prime}(c)}=0
$$

which obviously comes from (B7). Constraint (B5) ensures that it has at least one positive real root. So, for any fixed $a$, there exists a value for $m_{0}$ that will yield a solution for (B4). Since $a$ can be any number on $(0,1)$, there are uncountable solutions for (B4).

It should be emphasized that constraint (B5) was imposed to ensure existence of the solution, not to ensure multiplicity. In other words, given the existence, nonuniqueness naturally arises. When the model has multiple solutions several possibilities 
arise. For instance, one may assume that the initial real quantity of money is given by the condition

$$
m(0)=\frac{M_{0}}{p\left(0^{-}\right)}
$$

where $M_{0}$ is the exogenous initial nominal stock of money. That amounts to say that the initial price level is not allowed to jump at the moment people learn that the economy entered at a hyperinflationary path.

\section{Appendix C}

In this Appendix we discuss some technical issues we have not gone through so far. For a while, we will stick to the assumption that the money demand is inelastic with respect to the interest rate.

As previously mentioned, we want our model to yield a hyperinflation path without violating the government budget constraint. We implicitly assume that there exists a path for $m$ that respects (B1), so that our exercise is not an empty one.

If no such path existed, we could still relax the hyphotesis that the initial price level $p(0)$ is exogenous and let it increase (so that the initial value of the real balances would fall) up to the point that was possible to find a path for $m$ to balance the government budget. In other words, we want $f, v$ and $u$ be such that the set of functions $m(\cdot)$ that satisfies

$$
\int_{0}^{t_{h}} e^{-\rho t}[s(m(t))-f(t)] d t>0
$$

is not empty. Since $s$ is positive, it is clear that for $f$ sufficiently low there will be such an $m(\cdot)$. 
Constraint $(\mathrm{C} 1)$ is required to ensure that the government can balance its budget. However, to ensure that the model generates a hyperinflation path another condition is required. Namely, we need to ensure that terminal inflation tax can finance terminal fiscal deficit and a decrease in real balance.

As shown in Barbosa e Cunha (2003), if the money demand is inelastic with respect to $r$, then money is essential. That is, $\lim _{m \rightarrow 0^{+}} m v^{\prime}(m)>0$. Now, use equation (6) to define $\pi$ as function of $m$. This procedure allows us to write the inflation tax as

$$
\pi(m) m=\frac{m v^{\prime}(m)}{u^{\prime}(c)}-\rho m
$$

From the government flow budget constraint (5), it is easy to verify that as $m$ decreases to zero, it must be the case that $f(t)<\pi(t) m(t)$. Combining this last fact with the above equality, we conclude that the condition

$$
f\left(t_{h}\right)<\frac{1}{u^{\prime}(c)} \lim _{m \rightarrow 0^{+}} m v^{\prime}(m)
$$

must hold for the model to display a hyperinflation path.

We now relax the hypothesis that money demand is inelastic with respect to the nominal interest rate. Condition $(\mathrm{C} 1)$ is still needed to ensure that the government balances its budget.

An important difference that arises when we remove our hypothesis on the money demand elasticity is the shape of the curve $m_{t}$ in Figure 4. It is not possible to ensure that this curve is decreasing with respect to time. However, it still is possible for the model to display an increasing inflation path. A necessary condition for this is

$$
\rho m(0)+f(0)-s(m(0))<0 .
$$




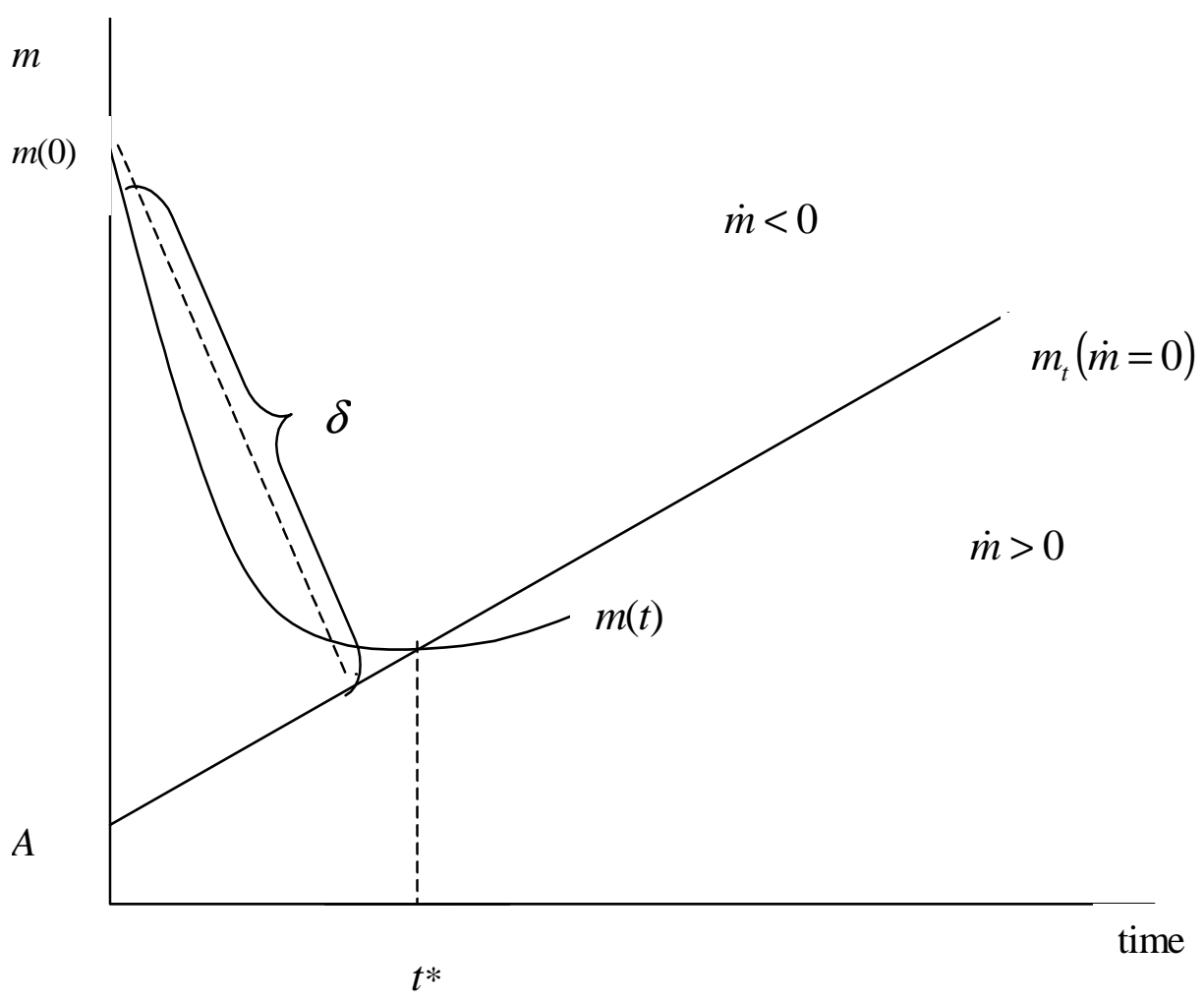

Figure 5

Figure 5 illustrates the solution of the model. Constraint (C3) ensures that $m(0)$ is above the intercept $A$. The solution path for $m$ is given by the curve $m(t)$. Observe that at date $t^{*}$ we have $\dot{m}=0$ and for larger dates, $\dot{m}>0$. So, inflation would be decreasing after date $t^{*}$. To avoid this, we need a requirement similar to constraint $(\mathrm{C} 2)$.

Let $\delta$ be the distance between the point $A$ and the locus $m_{t}$ (see Figure 5). We require that the terminal date $t_{h}$ not to be very large. In other words, $t_{h}$ must satisfy the boundedness constraint

$$
f\left(t_{h}\right)<\inf _{m \geq 0}\{\pi(m) m:|m-m(0)|<\delta\} .
$$

This constraint ensures that the solution must satisfy the condition $f(t)<\pi(t) m(t)$. So, the government budget constraint (5) implies $\dot{m}<0$ and the inflation is increasing. In other words, constraint (C4) guarantees that real balance path does not intersect the threshold $m_{t}$ before $t_{h}$. 
An important difference from the above solution and the one for the case in which the money demand is inelastic with respect to the interest rate is the value of the real balances at the end of the hyperinflation. In the present context, $\lim _{t \rightarrow t_{h}^{-}} m(t)>0$ is positive. Hence, the inflation does not diverge to infinite.

Assuming that the money demand is interest-rate inelastic indeed generates a more elegant solution, since that hypothesis allows inflation to explode in finite time. However, we would like to emphasize that all hyperinflation episodes in history ended while the inflation was still bounded. Hence, to account for the observed hyperinflation phenomena we do not need to make that assumption.

\section{REFERENCES}

Barbosa, Fernando de Holanda and Cunha, Alexandre B. (2003). Inflation tax and money essentiality. Economics Letters 78, 187-195.

Blanchard, Olivier J. and Fischer, Stanley (1989). Lectures on macroeconomics. Cambridge: The MIT Press.

Bresciani-Turroni, Constantino (1937). The economics of inflation: a study of currency depreciation in post-war Germany 1914-1923. London: George Allen \& Unwin.

Bruno, Michael and Fischer, Stanley (1990). Seigniorage, operating rules and the high inflation trap. Quarterly Journal of Economics 105, 353-374.

Cagan, Phillip (1956). The monetary dynamics of hyperinflation. In: Friedman, Milton. Studies in the quantity theory of money. Chicago: The University of Chicago Press.

Drazen, Allan and Helpman, Elhanan (1990). Inflationary consequences of anticipated macroeconomic policies. Review of Economic Studies 57, 147-166. 
Flood, Robert and Garber, Peter (1980). An economic theory of monetary reform. Journal of Political Economy 88, 24-58.

Friedman, Milton (1970). The counter-revolution in monetary theory. Wincott Memorial Lecture.

Kiguel, Miguel (1989). Stability, budget deficits and the dynamics of hyperinflation. Journal of. Money, Credit and Banking 21, 148-157.

Marcet, Albert and Nicolini, Juan P. (2003). Recurrent hyperinflations and learning. American Economic Review 93, 1476-1498.

Obstfeld, Maurice and Rogoff, Kenneth (1996). Foundations of international macroeconomics. Cambridge: MIT Press.

Romer, David (2001). Advanced macroeconomics. Second edition. New York: McGrawHill.

Sargent, Thomas J. (1982). The ends of four big inflations. In: Hall, Robert. Inflation, causes and effects. Chicago: The University of Chicago Press.

Sargent, Thomas J. (1987). Dynamic macroeconomic theory. Cambridge: Harvard University Press.

Sargent, Thomas J. and Wallace, Neil (1987). Inflation and the government budget constraint. In: Razin, Assaf and Sadka, Efraim. Economic policy in theory and practice. New York: Macmillan.

Trehan, Bharat and Walsh, Carl E. (1991). Testing intertemporal budget constraints: theory and applications to U.S. federal budget and current account deficits. Journal of Money, Credit and Banking 23, 206-223.

Zarazaga, Carlos E. J. M. (undated). "Recurrent Hyperinflations in a Dynamic Game with Imperfect Monitoring in the Appropriation of Seignorage." Mimeo. 


\section{Últimos Ensaios Econômicos da EPGE}

[553] Daniel Gottlieb, Aloisio Pessoa de Araújo, e Humberto Luiz Ataide Moreira. A model of mixed signals with applications to countersignaling an the GED. Ensaios Econômicos da EPGE 553, EPGE-FGV, Jul 2004.

[554] Lucas Jóver Maestri e Carlos Eugênio Ellery Lustosa da Costa. The riskproperties of human capital and the design of government policies. Ensaios Econômicos da EPGE 554, EPGE-FGV, Jul 2004.

[555] Daniel Gottlieb e Lucas Jóver Maestri. Banning information as a redistributive device. Ensaios Econômicos da EPGE 555, EPGE-FGV, Jul 2004.

[556] Leonardo Pio Perez e Pedro Cavalcanti Gomes Ferreira. Efeitos macroeconômicos e custos sociais de uma transição entre regimes de previdência no Brasil. Ensaios Econômicos da EPGE 556, EPGE-FGV, Jul 2004.

[557] Rubens Penha Cysne. Inflation and income inequality: A link through the jobsearch process. Ensaios Econômicos da EPGE 557, EPGE-FGV, Ago 2004.

[558] Rubens Penha Cysne. A search-theoretic explanation for the negative correlation between labor income and impatience. Ensaios Econômicos da EPGE 558, EPGE-FGV, Ago 2004.

[559] Rubens Penha Cysne. Income inequality:The role of impatience in a job-search process. Ensaios Econômicos da EPGE 559, EPGE-FGV, Ago 2004.

[560] Rubens Penha Cysne. Towards a measure of income inequality freed from the volatility caused by variations in the rate of unemployment. Ensaios Econômicos da EPGE 560, EPGE-FGV, Ago 2004.

[561] Rubens Penha Cysne. On the positive correlation between income inequality and unemployment. Ensaios Econômicos da EPGE 561, EPGE-FGV, Ago 2004.

[562] Rubens Penha Cysne. A general-equilibrium closed-form solution to the welfare costs of inflation (Forthcoming, Revista Brasileira de Economia). Ensaios Econômicos da EPGE 562, EPGE-FGV, Ago 2004.

[563] Marcelo Casal de Xerez e Marcelo Côrtes Neri. Aspectos dinâmicos de um sistema de metas sociais. Ensaios Econômicos da EPGE 563, EPGE-FGV, Ago 2004.

[565] Marcelo Casal de Xerez e Marcelo Côrtes Neri. Desenho de um sistema de metas sociais. Ensaios Econômicos da EPGE 565, EPGE-FGV, Set 2004. 
[566] Paulo Klinger Monteiro, Rubens Penha Cysne, e Wilfredo Maldonado. Inflation and Income Inequality: A Shopping-Time Aproach (Forthcoming, Journal of Development Economics). Ensaios Econômicos da EPGE 566, EPGE-FGV, Set 2004.

[567] Rubens Penha Cysne. Solving the Non-Convexity Problem in Some ShoppingTime and Human-Capital Models. Ensaios Econômicos da EPGE 567, EPGEFGV, Set 2004.

[568] Paulo Klinger Monteiro. First-Price auction symmetric equlibria with a general distribution. Ensaios Econômicos da EPGE 568, EPGE-FGV, Set 2004.

[569] Samuel de Abreu Pessôa, Pedro Cavalcanti Gomes Ferreira, e Fernando A. Veloso. On The Tyranny of Numbers: East Asian Miracles in World Perspective. Ensaios Econômicos da EPGE 569, EPGE-FGV, Out 2004.

[570] Rubens Penha Cysne. On the Statistical Estimation of Diffusion Processes A Partial Survey (Revised Version, Forthcoming Brazilian Review of Econometrics). Ensaios Econômicos da EPGE 570, EPGE-FGV, Out 2004.

[571] Aloisio Pessoa de Araújo, Humberto Luiz Ataide Moreira, e Luciano I. de Castro Filho. Pure strategy equilibria of multidimensional and Non-monotonic auctions. Ensaios Econômicos da EPGE 571, EPGE-FGV, Nov 2004.

[572] Paulo César Coimbra Lisbôa e Rubens Penha Cysne. Imposto Inflacionário e Transferências Inflacionárias no Mercosul e nos Estados Unidos. Ensaios Econômicos da EPGE 572, EPGE-FGV, Nov 2004.

[573] Renato Galvão Flôres Junior. Os desafios da integração legal. Ensaios Econômicos da EPGE 573, EPGE-FGV, Dez 2004.

[574] Renato Galvão Flôres Junior e Gustavo M. de Athayde. Do Higher Moments Really Matter in Portfolio Choice?. Ensaios Econômicos da EPGE 574, EPGEFGV, Dez 2004.

[575] Renato Galvão Flôres Junior e Germán Calfat. The EU-Mercosul free trade agreement: Quantifying mutual gains. Ensaios Econômicos da EPGE 575, EPGE-FGV, Dez 2004.

[576] Renato Galvão Flôres Junior e Andrew W. Horowitz. Beyond indifferent players: On the existence of Prisoners Dilemmas in games with amicable and adversarial preferences. Ensaios Econômicos da EPGE 576, EPGE-FGV, Dez 2004.

[577] Rubens Penha Cysne. Is There a Price Puzzle in Brazil? An Application of Bias-Corrected Bootstrap. Ensaios Econômicos da EPGE 577, EPGE-FGV, Dez 2004.

[578] Fernando de Holanda Barbosa, Elvia Mureb Sallum, e Alexandre Barros da Cunha. Competitive Equilibrium Hyperinflation under Rational Expectations. Ensaios Econômicos da EPGE 578, EPGE-FGV, Jan 2005. 